\title{
PAUTAS-BOMBA AMEAÇAM EXPLODIR O ORÇAMENTO DE 2019
}

Coluna publicada em 24.6.2018: <https://www.conjur.com.br/2018-jul-24/contasvista-pautas-bomba-ameacam-explodir-orcamento-2019>

Nas últimas semanas, o Congresso Nacional voltou com tudo ao noticiário. Não era para menos. Às vésperas de iniciar o recesso, precisava votar uma série de medidas, incluindo a Lei de Diretrizes Orçamentárias, sem o que o recesso não se inicia. ${ }^{1}$ A maioria delas com potencial explosivo para as contas públicas: as chamadas "pautas-bomba".

E desta vez o recesso será longo, pois, com eleições gerais para presidente, governadores, senadores e deputados no segundo semestre, é difícil que esse recesso acabe tão cedo. Tudo indica que não se deve votar mais nada relevante até dezembro. Exceto, evidentemente, a lei orçamentária, cuja aprovação deve (espera-se...) ocorrer até o final do ano.

O que se viu foi uma verdadeira guerra, um "agora ou nunca" ou "tudo ou nada” nas votações que marcaram esses primeiros dias de julho.

Em pauta, projetos de lei que aumentam os gastos públicos, como reajustes salariais, e outros que reduzem receitas. E aumentar despesas e reduzir receitas não parecem ser medidas alinhadas à responsabilidade fiscal que se almeja em momentos de crise fiscal aguda como essa que se perpetua já há alguns anos.

Destaque coube para as renúncias de receitas, abrangendo benefícios fiscais e creditícios de toda sorte, que têm se transformado em um problema de irresponsa-

1 Ou não deveria iniciar, já que temos visto essa norma ser "driblada" nos últimos anos... Falou-se sobre isso em 2015: o ano de triste memória para o Direito Financeiro que não quer terminar, nesta edição, p. 483-488. 
bilidade fiscal cada vez mais grave. ${ }^{2}$ Perdão de dívidas para produtores rurais e microempresas e compensação dos estados pela desoneração do ICMS sobre exportações, entre outros benefícios fiscais, têm potencial para provocar estragos no orçamento federal da ordem de $\mathrm{R} \$ 100$ bilhōes, ${ }^{3}$ o dobro do que se gasta com o custeio da máquina pública. ${ }^{4}$

Vê-se que o governo, na tentativa de manter - ou, melhor dizendo, tentar recuperar - o equilíbrio orçamentário, perdido já há alguns anos, em que se sucedem os déficits, dadas as reiteradas práticas de irresponsabilidade fiscal, manda projetos para conter o ímpeto de gastar mais e mais dinheiro público (isso quando consegue resistir às pressões de todos os lados, o que nem sempre acontece, e o próprio governo boicota as contas públicas). Os projetos que tentam defender o orçamento público, no entanto, sofrem impiedosos ataques ao chegar ao Congresso, que, armado de emendas parlamentares que os congressistas usam como se fossem fuzis russos AK-47, desconfiguram o texto encaminhado, e do que é aprovado pouco sobra para manter o equilíbrio das contas públicas.

Um cenário que diminui as perspectivas de ajuste nas contas governamentais coloca em risco a "regra de ouro", já na iminência de ser violada, ${ }^{5}$ aumentando o risco de endividamento excessivo, deixando dúvidas sobre o efetivo respeito à "Emenda do Teto de Gastos” e tornando sombrio o futuro de nossas finanças públicas.

Releva notar que, das medidas em discussão, várias são autônomas. Mas muitas foram inseridas no bojo da Lei de Diretrizes Orçamentárias, cuja aprovação é "obrigatória" antes do recesso parlamentar.

2 Veja, a título de exemplo, a reportagem que estampa a manchete da Folha de S.Paulo de domingo (22/7): "Governo desperdiça 173 bi em programas sem retorno: avaliação de subsídios federais em 20 projetos identificou que 4 não tiveram efeito".

3 Em estimativa da revista IstoÉ Dinheiro: Refis do Simples - R \$ 7,8 bilhões; Refis do Funrural - R\$ 13 bilhões; compensações da Lei Kandir - R\$ 39 bilhões; benefícios fiscais para transportadoras - R \$ 27 bilhões; venda direta de etanol aos postos - R \$ 2,4 bilhôes; reinstituição de benefício ao setor de bebidas - R \$ 1,8 bilhão; benefícios fiscais Sudene e Sudam - R \$ 9,3 bilhōes; transferência de servidores de ex-territórios da União - R \$ 2 bilhões; e derrubada do adiamento a reajuste de servidores em 2019 - R \$ 11 bilhōes (Uma bomba nos gastos públicos. IstoÉ Dinheiro, n. 1079, 25 de julho de 2018, p. 18-23). E ainda: "A pauta-bomba de 100 bi do Congresso prova: no Brasil, o que é ruim pode piorar", in portal InfoMoney (www.infomoney. com.br), em 12 de julho de 2018.

4 Conta de pautas-bomba é equivalente ao dobro do custeio da máquina pública. Folha de S.Paulo, 12 de julho de 2018.

5 Veja recente coluna de Élida Pinto, Diante da iminente ruptura da regra de ouro, LDO 2019 limita renúncias fiscais, publicada em 17 de julho de 2019 no ConJur.

6 EC 95/2016, que instituiu o Novo Regime Fiscal. 
Um fato que chama a atenção para a questão da exclusividade orçamentária, que está se transformando em um problema no âmbito do Direito Financeiro. Uma oportunidade para dar o devido destaque a esse tema.

Aproveitando-se do momento e da necessidade de rápida aprovação das medidas, o que se viu foi uma série de inserções de dispositivos na Lei de Diretrizes Orçamentárias que não necessariamente têm relação com suas funções constitucionais.

A Lei de Diretrizes Orçamentárias (LDO), sobre a qual já houve referência expressa e destacada em colunas anteriores, ${ }^{7}$ é por excelência um instrumento de planejamento orçamentário, cujas funções estão expressamente previstas na Constituição (art. 165, \$ $2^{\circ}$ ) e na Lei de Responsabilidade Fiscal (art. 4o). Deve cuidar essencialmente de orientar a elaboração da lei orçamentária anual e definir as prioridades orçamentárias, no que foi importante para dar maior relevância ao papel do Poder Legislativo no processo orçamentário.

O uso cada vez mais intenso - mas não necessariamente correto - da LDO para dispor sobre toda e qualquer questão que envolva direta ou indiretamente temas financeiros evidencia cada vez mais a importância que essa lei tem assumido no cenário legislativo e a coloca no caminho de disputar com a lei orçamentária o título de lei mais importante depois da Constituição. ${ }^{8} \mathrm{~A}$ essa altura já deve ser possível considerá-la a segunda mais importante. Menos mal. Perdemos a Copa do Mundo, mas em matéria de importância o Direito Financeiro já está com a medalha de ouro e prata, e as outras leis ficam com a disputa do bronze.

Entre os vários pontos polêmicos, alguns merecem atenção. A LDO entrou em detalhes em temas como proibição do reajuste de verbas destinadas aos gabinetes de parlamentares, proibição de compra ou reforma de residências oficiais, aquisição de automóveis por autoridades, pagamentos de diárias, detalhamentos relacionados a nomeações de servidores públicos e reajustes para gastos em procedimentos na área da saúde, entre muitos outros.

O princípio da exclusividade orçamentária é antigo, já consta de nossa Constituição desde o texto de 1926, sendo amplamente acolhido pelo sistema legislativo orçamentário do mundo todo. Preconiza a vedação da inclusão na lei orçamentária de "dispositivo estranho à previsão de receita e à fixação da despesa" (Constituição, art. $\left.165, \$ 8^{\circ}\right)$, para limitar o uso da lei orçamentária ao tema que lhe é próprio.

7 LDO é instrumento eficiente para a administração pública, nesta edição, p. 151-154, e Decisões financeiras fundamentais são tomadas na Lei de Diretrizes Orçamentárias, nesta edição, p. 155-160.

8 "A lei orçamentária é a lei materialmente mais importante do ordenamento jurídico logo abaixo da Constituiçãa”, min. Carlos Britto, p. 92 dos autos, STF, Tribunal Pleno, ADI 4.048 (rel. Min. Gilmar Mendes, j. 14.5.2008). 
O orçamento público já foi, em face principalmente de seu processo legislativo periódico e acelerado, utilizado como meio para a inserção de dispositivos não relacionados a seu conteúdo específico, criando as "caudas orçamentárias" - ou, ainda, "orçamentos rabilongos", para usar expressão criada por Rui Barbosa.

No entanto, a literalidade de nossa Constituição, ao proibir tais disposições na "lei orçamentária", foi silente com relação à "lei de diretrizes orçamentárias", permitindo que uma interpretação literal e restritiva admita usar a LDO para dispor sobre temas que tem duvidosa pertinência com as funçôes que lhe são próprias.

E o que se vê, pelos exemplos citados, é uma verdadeira "LDO rabilonga", com dispositivos casuísticos, repleta de normas que pouca relação e utilidade tem com o sistema de planejamento orçamentário.

A amplificação do uso da LDO é notória. A primeira LDO federal tinha 59 artigos (Lei 7.800, de 10 de julho de 1989); a atual, 157 artigos (Lei 13.473, de 8 de agosto de 2017); e o projeto sobre o qual se falou nesta coluna, 149 artigos, sem contar os vários anexos. Um inchaço que mostra, de um lado, a importância que a LDO tem assumido na condução da administração pública; de outro, porém, o "efeito-carona" que está ocorrendo nessa lei ao ser utilizada para agregar temas que não estão em sua abrangência funcional.

Um grande equívoco que precisa ser desfeito. O princípio da exclusividade orçamentária precisa ser revisitado, e a LDO, retomar seu caminho, sem deixar que se desvie para se transformar em uma "colcha de retalhos". Em recente obra sobre o tema, Weder de Oliveira destaca que as leis orçamentárias têm funções constitucionais próprias e específicas que permitem conferir ao PPA e à LDO a estatura de "leis reforçadas", conforme construção do Direito português (com destaque para Carlos Blanco de Morais e Jorge Miranda), dando-lhes supremacia sobre as demais. Forma-se, assim, um todo lógico e coerente de planejamento orçamentário da administração pública pela tríade PPA-LDO-LOA. Para isso, exige-se o rigoroso respeito por esses diplomas normativos de dispor sobre as funções que lhes são próprias. Assim sendo, o princípio da exclusividade estende-se às demais leis orçamentárias, que devem tão somente tratar das matérias que lhes são próprias, em razão da função específica que a Constituição lhes definiu dentro do sistema orçamentário. Não se pode admitir, assim, que a LDO, como tem ocorrido frequentemente, supra as lacunas da Lei 4.320 e disponha sobre temas que não lhe são próprios, como regramentos detalhados de execução orçamentária. E alerta: "Independentemente do mérito do conteúdo extraconstitucional, enquanto as leis de diretrizes orçamentárias avançam irrestritamente em espaços legislativos não ocupados pelo ato legislativo competente (lei complementar, lei orçamentária, leis 
ordinárias), suas expressas funçôes constitucionais esmaecem na mesma proporção, concorrendo essa prática para distanciar a LDO de seu sentido no sistema e de sua gênese: ser o lócus dos grandes debates e decisões orçamentárias, macroeconômicas e de políticas públicas, dando-se, assim, plena razão aos seus críticos históricos".?

Portanto, muito mais adequado do que ater-se à literalidade do texto constitucional, que faz referência ao princípio da exclusividade orçamentária apenas para a lei orçamentária anual, é ter a compreensão sistemática e teleológica da Constituição para reconhecer as funçóes constitucionais de cada uma das leis e ver que a LDO não se presta a atender casuísmos que pouca ou nenhuma relação tem com o planejamento orçamentário. Devemos ater-se à sua conformidade funcional para não admitir as verdadeiras "caudas" que estão sendo indevidamente anexadas à LDO, voltando décadas atrás na evolução das leis orçamentárias.

Tudo isso mostra que não são apenas as nossas contas públicas que estão sob ataque, mas também o Direito Financeiro.

E, não obstante iniciado o recesso do Congresso Nacional, não se pode esperar que a trégua dure muito. No final de agosto, tão logo apresentada a proposta de lei orçamentária para 2019, abre-se o cofre da "cota parlamentar" e entra em cena o Partido de Caça aos Convênios, ao qual todos parecem pertencer nesse período, com os parlamentares em busca de transferências voluntárias ${ }^{10}$ para atender às suas bases eleitorais e garantir a reeleição - o que, convenhamos, agrava-se sobremaneira durante esse período de campanha eleitoral.

Assim fica difícil levar o Direito Financeiro a sério...

9 Lei de Diretrizes Orçamentárias: gênese, funcionalidade e constitucionalidade - retomando as origens. Belo Horizonte: Fórum, 2017. p. 404.

10 Transferências voluntárias geram desequilíbrio federativo, nesta edição, p. 19-22. 
